\title{
Developing Immersive Simulations: The Potential of Theater in Teaching and Learning in Political Studies
}

Rod Dacombe, King's College, London

Elizabeth A. Morrow, University of Birmingham

ABSTRACT Innovative teachers of political science have frequently moved beyond the confines of conventional teaching formats to better engage students with the demands of the discipline. In particular, the use of simulations has been proposed as an alternative to passive, lecture-based techniques, and a growing literature examines their value and efficacy. This article contributes to the literature by describing the development of a simulation that draws on the principles of immersive theater in an attempt to maximize participation while encouraging students to think critically about political concepts and ideas.

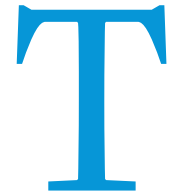
he literature on teaching and learning in political science articulates a concern about the variety and effectiveness of "conventional" means of teaching politics students (Omelicheva and Avdeyeva 2008). Increasingly, researchers have highlighted problems related to the complexity of political ideas and their application, their sometimes abstract nature, and the need for the necessary knowledge of political systems to fully appreciate the issues at hand (Payerhin 2003). At the same time, students' diverse learning preferences mean that teaching methods rooted in wellestablished class formats can fail to properly satisfy the needs and expectations of many (Damron and Mott 2005; Fox and Ronkowski 1997; Loggins 2009).

In this context, the use of simulations has been proposed as an effective alternative. Simulations-that is, simplified representations of an external reality used to promote cooperative or problembased learning-have been found to more effectively engage students, develop cognitive skills, and foster a sense of ownership than more passive approaches to learning (Dorn 1989). Simulations can be useful because they require a degree of student participation that is not necessary in more passive learning techniques, and they bring theoretical insights directly to bear on practical examples.

This article extends this discussion to prompt thought on innovation in teaching political science. It explores ways that insights drawn from immersive theater may be used to communicate political ideas in the classroom. This discussion of our experiences in developing an undergraduate simulation using

Rod Dacombe is lecturer in politics in the Department of Political Economy at King's College, London. He can be reached at rod.dacombe@kcl.ac.uk.

Elizabeth A. Morrow is a research fellow in political science and international studies at the University of Birmingham. She can be reached at morrowe@bham.ac.uk immersive-theater principles demonstrates its potential to develop teaching approaches that strongly engage students in theoretical problems while encouraging negotiation, communication, and teamwork skills. Our experiences suggest that close attention to developing and planning simulations, as well as a structured period of reflection after the sessions, is particularly important in ensuring their success.

The article first summarizes the value of simulations as teaching and learning tools in political science. It then outlines the development of our simulation in collaboration with Coney, a theater company specializing in immersive performances. Following this, the piece sketches the translation of the simulation to the classroom, outlining the main learning points at each stage, in the context of existing literature. The article highlights the value of reaching beyond the boundaries of political science when developing teaching practice and identifies the main benefits of the collaboration. Two appendices (online) are included that provide further information on background and development, as well as details on the simulation itself to aid in replication.

\section{USING SIMULATIONS IN POLITICAL SCIENCE}

Innovative teachers of political science frequently move beyond the confines of conventional classroom formats to better engage audiences with the demands of the subject (Moran 2013; Schaap 2005; Woodcock 2006). For instance, Laver famously used games as a teaching tool to demonstrate the complexity of political interactions. His book, Playing Politics (1979), made a compelling case for the potential of developing forms of teaching that make political concepts accessible to a wide audience. Similar concerns motivated Schaap's (2005) use of role play in political-theory classes, Smith's (2012) game used to illustrate Duverger's Law to undergraduates, and even Woodcock's (2006) use of The Simpsons as a way to shape classroom discussions on political theory and democracy. 
What is common to each of these approaches is the idea that learning need not be a passive activity, but an active encounter where students have agency over their engagement with the topic that benefits their learning experience. Viewing teaching in this way can create an environment in which the pedagogical relationship between teacher and student is not defined according to the norms of a conventional university classroom-a significant point given that the ability to vary the form and method of instruction for political science students is central to recent
Creating immersive experiences gives audience members control over the choices they make in the performance. Depending on their decisions, their interaction with one another, and their engagement with the narrative structure of the piece, any two performances are very different indeed (Nield 2008).

Most practitioners of immersive theater are explicit about their aims to challenge the bias and prejudice of their audience. For some, this is a consciously political act; as Bray and Chappell $(2005,92)$ noted: "[t]heater...is a form of communication that

\section{Viewing teaching in this way can create an environment in which the pedagogical relationship between teacher and student is not defined according to the norms of a conventional university classroom - a significant point given that the ability to vary the form and method of instruction for political science students is central to recent thought on teaching practice.}

thought on teaching practice. There is widespread recognition that students have a range of different learning preferences, not all of which can be met through traditional approaches to teaching (Brock and Cameron 1999; Fox and Ronkowski 1997).

The emergence of simulations as a classroom tool to alleviate these types of problems is well documented (for useful accounts, see Asal and Blake 2006; Frederking 2005; Smith and Boyer 1996). The value in exposing students of political science to these types of activity is that they are required to work together to solve the problems presented to them, and good simulations will clarify the theoretical grounding of the activity. As Damron and Mott $(2005,368)$ suggested, "[ $\mathrm{t}]$ he task in all political science classes is to teach students to think critically about key concepts and ideas rather than just play the game of demonstrating that they can define those concepts and ideas." Cooperative and problemsolving classroom activities encourage students to critically analyze and apply political concepts rather than simply demonstrate their comprehension of them. The challenge, of course, is to devise simulations that are appropriate to the class and the audience and to use them in a way that maximizes student engagement while rigorously exploring theory.

Our experiences in the classroom underlines these points. We were concerned that our largely theoretical undergraduate module on democratic ideas would lose traction when students examined contemporary political problems in class. In response, we developed a simulation that directly addressed the themes covered in the module, but we encouraged our students to approach them in ways that they self-determined.

\section{DEVELOPING THE SIMULATION}

Our approach to developing the simulation had a unique background. During the early stages, we worked closely with Coney, a theater company specializing in immersive techniques (see appendix 1 for more information about the project). Immersive theater is distinguished by its treatment of the audience and is described as a "theatre of experience" (Groot Nibbelink 2012, 416). Whereas conventional theatrical performances feature an actor performing a role on stage, immersive theater brings the audience center stage, making them witnesses, actors, and directors and blurring the distinction between theater and life. discloses aspects of political reality that would not be understood without it." To achieve this, performances adapt to make use of different spaces and frequently move out of theaters and galleries to take place in "everyday" or "found" spaces (White 2012). Significantly, the interplay among the space, plot, and background information provided during performances (i.e., in the form of text, props, and conversations with actors) is not comprehensive. Therefore, the "imaginative filling-in of gaps" by the audience is important in understanding the degree of control they have over the performance (White 2012, 231).

Our work with Coney originally focused on developing a theatrical performance that dealt with political theory and whose guiding principles were adapted in our classroom simulation. The performance, titled "Early Days of a Better Nation," placed the audience as the nascent government of a fictional country emerging from the ruins of a civil war. Participants were divided into four "regions" and given information relating to the political state of their region through secret letters, "covert" radio broadcasts, and conversations with professional actors. From this starting point, the audience was tasked with rebuilding the political system and was presented with a series of collective-action problems that required both cooperation and compromise to be successfully resolved. The piece was unique in its aim to introduce audience members to political ideas through direct participation in discussion, negotiation, and problem solving.

As part of the development, we contributed to four preview performances held by Coney, three of which were open to members of the public and one to university students and staff. These performances served as a test-run for Coney and were designed to elicit audience feedback. Each performance concluded with a debriefing session that focused on putting the audience's experiences of the performance in the context of its theoretical underpinnings. These sessions proved invaluable; it quickly became clear that a period of reflection and discussion enabled participants to consider their individual experiences of the performance far more critically than otherwise would have been the case.

\section{BRINGING THEATER TO THE CLASSROOM}

Our work with Coney raised two major points that influenced our thoughts on the ways in which simulations can be run, 
particularly in large groups. First, simulations can benefit not only from a focus on the types of tasks allocated to participants but also from a serious consideration of the story arc through which students are guided during the class. A strength of the Coney performances was the use of dramatic devices to engage the audience in complex ideas which reinforced the theoretical themes encountered during the performance, and we aimed to harness this in a classroom setting. Second, the freedom of audience members to decide for themselves the direction of the performance was important. The immersive approach provided a framework within which audience members could encounter numerous theoretical questions without dictating either the order of the piece or the outcome. As teachers, we found this fascinating. Too often, course curricula are decided and rigidly imposed by instructors, with little thought given to the differing ways in which students might encounter the problems. In contrast, these techniques allowed a degree of student ownership that is rarely possible in the classroom.
(3) engaging students in theoretical questions by addressing them through the narrative structure of the simulation.

As previous literature on simulations indicates, implementing this type of approach requires careful consideration and planning; a clear focus on the various stages involved in the planning and execution of the class is also important (Asal and Blake 2006). Students need to be engaged at each stage in the process, and careful consideration must be given to the learning objectives of the course, the types of students involved and the roles they are required to play, the organization of the session and-importantlythe use of debriefing sessions to facilitate critical thought about the issues built into the simulation (Loggins 2009).

\section{REBUILDING DEMOCRATIA: A CLASSROOM SIMULATION}

When crafting our simulation, we were guided by Asal and Blake (2006), who have established a process that is informed by previous literature and conducive to creative classroom engagement with political science. They separated the management of

\section{The immersive approach provided a framework within which audience members could encounter numerous theoretical questions without dictating either the order of the piece or the outcome.}

We worked with Coney in translating the principles of the "Early Days" performance to the classroom and encountered several distinct challenges. The class in question was an undergraduate module focusing on democratic theory. For a large class (i.e., weekly attendance averaged 60 to 70 students), running a successful simulation would require an approach that relied on participation of the class as a whole as well as in smaller groups. This matched the experience of the theatrical performances, in which audiences were approximately the same size. The learning outcomes for the topic addressed by the simulation were to introduce students to contemporary issues in representative democracy through an examination of democratic theory and to develop their communication and teamwork skills.

From the outset, it was clear we were producing a class that was distinct from conventional simulations. In addition to providing a basic structure for the session, adapting the theatrical performances allowed elements of emplotment to be introduced into the simulation. The narrative structure of the "Early Days" performance underpinned the simulation; conversations with the instructor took the place of encounters with professional actors in the performance and elements of staging were introduced to enhance student engagement with the session. Beyond this, we worked with Coney to create an environment in which students addressed the topic at hand but were free to adapt and imagine their roles. This was a direct use of an important element of immersive practice in the simulation.

We believed that devising a simulation that followed the insights of immersive theater in this way would improve the classroom experience in three ways: (1) moving the class away from the norms of standard teaching formats would allow students considerable leeway in the structure and direction of the session; (2) utilizing the classroom setting in new ways by reordering the space and introducing elements of staging; and a simulation into three discrete stages: preparation, interaction, and debriefing. We adapted these principles in the development and delivery of the session.

\section{Preparation}

Our simulation took place midway through the term, after the introductory elements of the course had been covered, and focused on representation, exploring fundamentals of democratic theory in the area. One week before the simulation, an introductory lecture described the main themes to be explored by the exercise. After the lecture, students were given a reading list to be completed in advance of the simulation as well as questions to consider when working through the literature. Limited information on the session itself was provided other than that they would participate in a class-wide simulation.

\section{Interaction}

The class was divided into small groups of approximately eight students each to represent the regions of a fictional nation (i.e., Democratia). The students were given a booklet that described the social and economic history of their particular region-as well as the nation as a whole-including the recent descent into civil conflict, which had been abandoned in stalemate. Students also were provided a written constitution that established a framework for the session. Maps of Democratia were projected on the walls and the classroom was divided into distinct "regions." Chairs in the front of the room were arranged to resemble a parliamentary assembly.

Each region elected a single representative to a "national assembly" for a term of 10 minutes, during which the representatives would deliberate and pass legislation before returning to their region for a mandatory election. The program of legislation was designed in advance and explicitly focused on the themes addressed in the lecture and reading assignments. Importantly, although 
the format for the session was provided and facilitated by an instructor (acting as the "Speaker" of the assembly), students were free to change the structure of the simulation, as long as they abided by a few basic rules (e.g., by proposing new legislation or forcing a constitutional amendment).

When the ground rules of the session were understood, students were immediately tasked with holding an election. Coney's theatrical performances had highlighted the importance of momentum with sessions involving numerous participants; the brief periods between elections along with the prepared program of work ensured that participation was maintained from the outset. Students addressed any questions concerning the rules of the session to the instructor, who responded in his or her role as the "Speaker."

\section{Debriefing and Reflection}

The final half hour of the session was dedicated to a structured debriefing of the simulation. In their "regions," students were asked to prepare a brief account of the main lessons learned from the simulation, focusing particularly on links to the theoretical content of the literature covered in the previous week. This activity continued for a few days after the session. The instructor posted reflections on the course Virtual Learning Environment and students were encouraged to respond, either in the same manner or in a series of follow-up sessions at the end of the course.

\section{STUDENT RESPONSES}

Student responses to the simulation were overwhelmingly positive: when asked to score the session on a 5-point scale, the overall rating was 4.97. During the debriefing and follow-up sessions, participants contrasted the session favorably with their previous classroom experiences and highlighted the particular benefits of exploring political ideas in this way. The debriefing sessions suggested that students appreciated the complexity of representation through the simulation and emphasized that their understanding of the topic was enhanced as a result.
Crucially, the participating students considered their involvement in the simulation in theoretical terms, linking the running of the simulation to the themes they encountered during the assigned reading. Another participant noted the following:

The simulation...was a great way to reinforce our understanding of how democracies operate. When divided into regions and representing our electorate on different issues, I felt like we ourselves fell prey to a lot of the usual "traps of democracy" that we'd been discussing. We became the aggressive, competitive, almost self-interested House of Cards politicians that we always complain about and often didn't look back and consult our group before making decisions in the "parliament."

Another student reflected as follows:

The simulation for the module worked well in illustrating how some aspects of theory are easier to apply to the real world than others! Bizarre to think pressure from the masses could initiate serious constitutional change, but mobilizing support helped do so during the exercise.

Of course, according to the literature, this is what we would expect because simulations have been found to develop students' comprehension and use of concepts (Asal and Blake 2006; Omelicheva and Avdeyeva 2008). However, by all accounts, the debriefing sessions allowed students to reflect on the simulation and consider the ways in which their actions and choices could be explained with reference to the literature.

\section{LESSONS FOR RUNNING IMMERSIVE SIMULATIONS}

Acting out political problems in this way is not suitable for all courses and will not satisfy all students. However, we found that the investment made in the narrative arc of the simulation paid dividends. Following the Coney performances, we wanted to "immerse" participants in the back story of their particular region and in the democratic process we had constructed for the session.

\section{What is particularly interesting, however, is the value that students found in the immersive techniques; the debriefing sessions and course evaluations all strongly suggested that students found it helpful to act out the theories they encountered and that the nature of the simulation benefited their engagement.}

What is particularly interesting, however, is the value that students found in the immersive techniques; the debriefing sessions and course evaluations all strongly suggested that students found it helpful to act out the theories they encountered and that the nature of the simulation benefited their engagement. Indeed, many participants reported that they felt that more theatrical elements might be introduced into the session because these made the simulation enjoyable and engaging. This raises the prospect of moving the simulation out of the classroom and perhaps holding sessions in government buildings or debate chambers. Additionally, the novel format of the class encouraged participation, as observed by one student: "I often find seminars intimidating, so it was good to do a group activity as getting to know my classmates helps develop my confidence."
The freedom allowed by the immersive structure provided this for the students. Almost immediately, participants amended the constitutional rules governing the session by abolishing gender restrictions on election and establishing term limits. They also began to pursue the interests of their particular region, electing officials who expressly addressed the issues identified in the background information.

The period of reflection was an equally essential part of the session. Regardless of the depth of engagement students felt in the simulation, it would have been of little pedagogical value without the space to reconnect the session with the literature on representation. The sustained period of reflection allowed students (and instructors) to make sense of what they had accomplished and to consider the learning outcomes of the session. 
As suggested by the literature, this was in many ways the most important part of the simulation (Asal and Blake 2006; Smith and Boyer 1996).

Of course, the diverse learning preferences of political science students mean that simulations like the one described in this article will never fully replace lecture-based courses as the primary means of teaching. However, we contend that our experiences underline the need to think carefully and creatively about the ways in which courses are conceived and delivered. It is a challenging experience to allow students the type of agency required in immersive approaches to simulation, and there is no doubt that introducing theatrical techniques in class is time-consuming and complicated. However, the potential to enhance student understanding of complex theoretical problems means that the use of simulations like ours needs to be accepted as an important part of the toolkit used by contemporary instructors.

\section{SUPPLEMENTARY MATERIAL}

To view supplementary material for this article, please visit https://doi.org/10.1017/S1049096516002456.

\section{REFERENCES}

Asal, Victor and Elizabeth L. Blake. 20o6. "Creating Simulations for Political Science Education.” Journal of Political Science Education 2 (1): 1-18.

Bray, Bernard L. and Larry W. Chappell. 2005. "Civic Theatre for Civic Education." Journal of Political Science Education 1 (1): 83-108.

Brock, Kathy L. and Beverly J. Cameron. 1999. "Enlivening Political Science Courses with Kolb's Preference Learning Model.” PS: Political Science \& Politics 32 (2): 251-6.
Damron, Danny and Jonathon Mott. 2005. "Creating an Interactive Classroom: Enhancing Student Engagement and Learning in Political Science Courses.” Journal of Political Science Education 1 (3): $367-83$.

Dorn, Dean. 1989. "Simulation Games: One More Tool on the Pedagogical Shelf." Teaching Sociology 17 (1): 1-18.

Fox, Richard L. and Shirley A. Ronkowski. 1997. "Learning Styles of Political Science Students." PS: Political Science \& Politics 30 (4): 732-7.

Frederking, Brian. 2005. "Simulations and Student Learning." Journal of Political Science Education 1 (3): 385-94.

Groot Nibbelink, Lisbeth. 2012. "Radical Intimacy: Ontroerend Goed Meets the Emancipated Spectator." Contemporary Theatre Review 22 (3): 412-20.

Laver, Michael. 1979. Playing Politics. New York: Penguin Viking.

Loggins, Julie A. 2009. "Simulating the Foreign Policy Decision-Making Process in the Undergraduate Classroom." PS: Political Science \& Politics 42 (2): 401-7.

Moran, Fran. 2013. "Fascist Pizza and the Lyceum Bakery: Remix, Mash-Up, and Student Generated Mixed Media in an Introductory Political Theory Course." Presented at the APSA Teaching and Learning Conference, Jersey City, NJ.

Nield, Sophie. 2008. "The Rise of the Character Named Spectator." Contemporary Theatre Review 18 (4): 531-44.

Omelicheva, Mariya Y. and Olga Avdeyeva. 2008. "Teaching with Lecture or Debate? Testing the Effectiveness of Traditional versus Active Learning Methods of Instruction.” PS: Political Science \& Politics 41 (3): 603-7.

Payerhin, Marek. 2003. "Have Case, Will Travel: Taking Political Science On (and Off) the Road." Political Science \& Politics 36 (3): 441-5.

Schaap, Andrew. 2005. "Learning Political Theory by Role Playing." Politics 25 (1): 46-52.

Smith, Elizabeth T. and Mark A. Boyer. 1996. "Designing In-Class Simulations.” PS: Political Science \& Politics 29 (4): 690-4.

Smith, Keith. 2012. "Why Just Two Parties? A Voting Game to Illustrate Duverger's Law." PS: Political Science \& Politics 45 (4): 759-64.

White, Gareth. 2012. “On Immersive Theatre.” Theatre Research International 37 (3): 221-35.

Woodcock, Pete. 2006. "The Polis of Springfield: The Simpsons and the Teaching of Political Theory." Politics 26 (3): 192-9. 